\title{
Potential influence of the first PCR cycles in real-time comparative gene quantifications
}

\author{
Hege Karin Nogva and Knut Rudi
}

BioTechniques 37:246-253 (August 2004)

\begin{abstract}
There is an underlying assumption in real-time PCR that the amplification efficiency is equal from the first cycles until a signal can be detected. In this study, we evaluated this assumption by analyzing genes with known gene copy number using real-time PCR comparative gene quantifications. Listeria monocytogenes has six $23 S$ rRNA gene copies and one copy of the hlyA gene. We determined $23 S$ rRNA gene copy numbers between 0.9 and 1.6 relative to hlyA when applying the comparative gene quantification approach. This paper focuses on the first cycles of PCR to explain the difference between known and determined gene copy numbers. Both theoretical and experimental evaluations were done. There are three different products (types 1-3) dominating in the first cycles. Type 1 is the original target, type 2 are undefined long products, while type 3 are products that accumulate during PCR. We evaluated the effects of type 1 and 2 products during the first cycles by cutting the target DNA with a restriction enzyme that cuts outside the boundaries of the PCR products. The digestion resulted in a presumed increased amplification efficiency for type 1 and 2 products. Differences in the amplification efficiencies between type 1, 2, and 3 products may explain part of the error in the gene copy number determinations using real-time PCR comparative gene quantifications. Future applications of real-time PCR quantifications should account for the effect of the first few PCR cycles on the conclusions drawn.
\end{abstract}

\section{INTRODUCTION}

PCR by itself is not a quantitative assay (1), but a complex series of chemical reactions, whose relative contributions to the overall process vary during early, middle, and late cycles. The mass balance between product, template, DNA polymerase, primers, and deoxynucleotides changes with each cycle. Similarly, hybridization interactions between complementary DNA molecules including primers, genomic template, and product are under continuous flux during PCR cycling.

PCR is modeled on the assumption that each DNA molecule can only be duplicated once with a probability $(P)$ during a cycle of amplification. The amplification rate of the reaction (x) is related to $P$, since $\mathrm{x}=1+P$. The duplication of each molecule is assumed to be independent of the duplication of other molecules (i.e., $P=1$ ). This seems like a fair assumption. PCR is usually conducted with an excess of reagents other than the DNA template, so that DNA molecules do not compete with each other for duplication. The amplification of a target of initial quantity is therefore assumed to proceed with the exponential accumulation of the product (2-4). Following this reasoning leads to the formula $\mathrm{N}_{\mathrm{n}}=2^{\mathrm{n}} \mathrm{N}_{0}$, which would be a convenient basis for the derivation of the initial copy number $\left(\mathrm{N}_{0}\right)$ from the size of the population after $\mathrm{n}$ cycles of amplification $\left(\mathrm{N}_{\mathrm{n}}\right)$.

However, PCR is not $100 \%$ efficient $(2,4)$. The efficiency of each cycle of PCR amplification is a function of the efficiency of primer binding and the proportion of molecules that extend to completion. These factors are controlled by many parameters, such as individual reaction component concentrations and types (i.e., $\mathrm{MgCl}_{2}$, DNA polymerase, template, and primers) as well as the optimization of temperature and time profiles and the extent and stability of the primer match with the template (5). Factors causing variable amplification rates during each cycle are probably more numerous than factors causing exactly the same amplification rate. In practice, these variables are generally subsumed into a single adjustment in the base " $x$ " of the equa- tion, and an average amplification rate is used for the calculation.

Higuchi and co-workers (6) described the simultaneous amplification and detection of specific DNA sequences and real-time PCR in the form of $5^{\prime}$-nuclease PCR. The 5'-nuclease PCR assay uses a nonextendable oligonucleotide hydrolysis probe, labeled with a reporter fluorophore at the $5^{\prime}$ end and a quencher fluorophore at the $3^{\prime}$ end, placed between the two primer binding sites. Because of the closeness of the quencher to the reporter emitter, the reporter fluorescence is suppressed, mainly by energy transfer of Förster-type (7). The parameter $\mathrm{C}_{\mathrm{T}}$ (cycle threshold) is defined as the fractional cycle number at which the reporter fluorescence is first detected. The target gene copy number in unknown samples may be quantified by measuring $\mathrm{C}_{\mathrm{T}}$ and using a standard curve, created by analyzing the $\mathrm{C}_{\mathrm{T}}$ values from the real-time PCR analyses of dilution series of known amounts of target to determine the starting copy number. The relative copy number can also be determined by comparing the 
$\mathrm{C}_{\mathrm{T}}$ values of the target gene with the $\mathrm{C}_{\mathrm{T}}$ values of a reference gene-if the amplification efficiencies of both reactions are similar (8).

Analyzing the kinetics of PCR product accumulation in the exponential phase and using a reference to eliminate the need of a standard curve and calibrate the amount of target are widely used to do comparative gene quantification. In this study, we evaluated the method using targets with known gene copy numbers. The complete genome sequence of Listeria monocytogenes is available (http://www.tigr.org). The genome contains 6 copies of the 23S rRNA gene and a single copy of the hlyA gene. We used this as a model in the evaluation of the real-time PCR comparative gene quantification method. We found a ratio of $23 \mathrm{~S}$ gene copies relative to hlyA gene copies between 0.9 and 1.6. It is clear that the comparative gene quantification method gives the wrong answer. Here we present a potential explanation for this discrepancy, which is caused by the amplification efficiency of the first PCR cycles. Both theoretical and experimental evidence is presented.

\section{MATERIALS AND METHODS}

\section{Bacterial Strains, Media, and Cultures}

Model organisms used were L. monocytogenes DSMZ $20600^{\mathrm{T}}$ (Deutsche Sammlung von Mikroorganismen und Zellkulturen $\mathrm{GmbH}$, Braunschweig, Germany) type strain; L. monocytogenes L028 wild-type (P. Cossart, Institut Pasteur, Paris, France); L. monocytogenes EGD-e serotype 1/2a (P. Glaser, Institut Pasteur); and L. monocytogenes isolate 2419 and isolate 3138 (L.-M. Rørvik, Norwegian College of Veterinary Medicine, Oslo, Norway).

All strains were plated on blood agar and grown in brain heart infusion (BHI) media at $30^{\circ} \mathrm{C}$. The agar and media were from Oxoid Ltd. (Basingstoke, Hampshire, UK).

\section{DNA Isolations and Restriction Enzyme Digestion}

DNA from approximately $10^{7} \mathrm{col}-$ ony-forming units (CFU) per sample was isolated using Dynabeads ${ }^{\circledR}$ DNA Direct I (Dynal AS, Oslo, Norway) or the DNeasy ${ }^{\circledR}$ tissue kit (Qiagen, Hilden, Germany). The DNA isolations were done as previously described by Nogva et al. $(9,10)$.

Approximately $0.1 \mu \mathrm{g}$ DNA was cut overnight at $37^{\circ} \mathrm{C}$ in a $50-\mu \mathrm{L}$ volume using $10 \mathrm{U}$ of restriction enzymes (New England Biolabs, Beverly, MA, USA). Complete digestion was verified by agarose gel electrophoresis. The controls in the subsequent PCR analyses were samples treated in the same way, but without restriction enzymes.

\section{TaqMan $^{\circledR}$ Probes and Primers}

GenBank ${ }^{\circledR}$ was searched for sequences of the L. monocytogenes 23S rRNA gene. Primers and probes were designed in a similar way as described by Nogva et al. $(9,10)$, following guidelines that have been previously described (11), using forward primer 5'-GTGTCAGGTGGGCAGTTTG-3' ${ }^{\prime}$, reverse primer 5'-CATTCTGAGGGAACCTTTGG-3', and probe $5^{\prime}$-CCTCCGTTACTCTTTAGGAGGCGACCG-3'. The probe contained 6-carboxy-fluorescein (FAM) as the fluorescent reporter dye covalently linked to the $5^{\prime}$ end, and the quencher dye 6-carboxy-tetramethylrhodamine (TAMRA) was covalently linked close to the $3^{\prime}$ end. The 76-bp DNA fragment (position 2260-2336 in GenBank accession no. X68420) was subjected to a FastA search (12) in the EMBL prokaryotic database (release 69; http://www.ebi.ac.uk/). Twenty reported Listeria sequences were identical in the positions of the primers and the probe, while no other organisms were reported to have identical sequences. In addition, the complete genome sequence of the L. monocytogenes EGD-e strain confirmed the sequence of the chosen fragment.

The primers and probes for the detection and quantification of the $L$. monocytogenes hlyA gene have been previously described (10). FAM reporter and TAMRA quencher were also used for the hlyA probe.

\section{Real-Time PCR Assays}

The $5^{\prime}$-nuclease PCR was carried out as previously described (10). Ef- ficiencies were calculated according to the method by Klein et al. (13), and the validation experiments were done as recommended by Applied Biosystems (14). The SYBR ${ }^{\circledR}$ Green assays (Applied Biosystems, Foster City, CA, USA) were done using the same conditions as for the $5^{\prime}$-nuclease PCR assays, following the recommendations of the manufacturer.

\section{Comparative Calculations}

Since the ratio between reference (hlyA) and target (23S) is assumed identical in all samples, the gene copy number of the target relative to the reference is estimated by the equation:

relative copy number $=$

$\mathrm{K}_{\mathrm{RS}} \times\left[\left(1+\mathrm{E}_{23 \mathrm{~S}}\right)^{\mathrm{CT} 23 \mathrm{~S}} /\left(1+\mathrm{E}_{\mathrm{hlyA}}\right)^{\text {CthlyA }}\right]$

where $\mathrm{E}$ is the calculated efficiencies, $\mathrm{C}_{\mathrm{T}}$ the cycle threshold, and $\mathrm{K}_{\mathrm{RS}}$ is the relative sensitivity of the target and reference (15). We used a modification of the $K_{R S}$ calculations because the formula presented by Ståhlberg et al. (15) assumes equal amplification efficiency from the first cycles until a signal can be detected. Our modification was that we used the multicomponent tool in the SDS 1.6 application software (Applied Biosystems) to determine the reporter signal five cycles before $\mathrm{C}_{\mathrm{T}}$. This was subtracted from the signal 15 cycles after the $\mathrm{C}_{\mathrm{T}}$. We used the following calculation for the relative sensitivity:

$$
\mathrm{K}_{\mathrm{RS}}=\mathrm{SENSTAR} / \mathrm{SENSREF} \text { [Eq. 2] }
$$

where SENSTAR is the difference in the signal for the target, and SENSREF is the corresponding value for the reference.

\section{Sequence Analysis}

The target sequences for both fragments from all strains included in this study (except EGD-e) were sequenced using ABI PRISM ${ }^{\circledR}$ Big Dye ${ }^{\mathrm{TM}}$ Terminator Cycle Sequencing Ready Reaction Kits, version 2.0, and an ABI PRISM Sequence Analyzer, model 310, version 3.0 (both from Applied Biosystems), according to the manufacturer's instructions.

In addition, the six 23S rRNA gene operons from the complete sequenc- 
ing of the L. monocytogenes EGD-e genome were aligned using Basic Local Alignment Search Tool (BLAST; http://www.ncbi.nih.gov/BLAST/).

\section{Secondary Structure Analysis}

The theoretical secondary structures for 400-500 bases surrounding the PCR fragments (type 1, template), the intermediate PCR fragments (type 2, long PCR products), and the PCR fragments (type 3, short PCR products) were analyzed using the DNA mfold server (http://www.bioinfo.rpi.edu/ applications/mfold/) (16), correcting the salt concentrations to $50 \mathrm{mM} \mathrm{Na}^{+}$(as a replacement for $\mathrm{K}^{+}$) and $5 \mathrm{mM} \mathrm{Mg}{ }^{2+}$, and at the annealing/extension temperature used in $5^{\prime}$-nuclease PCR $\left(60^{\circ} \mathrm{C}\right)$. The structures from the hlyA gene and the 23S rRNA gene were compared.

\section{RESULTS}

\section{Comparative Gene Quantification}

The quantitative properties of the 5 '-nuclease PCR assays were evaluated using a 2 -fold dilution series of DNA from several L. monocytogenes strains. The average amplification efficiencies for $23 \mathrm{~S}$ and $h l y A$ were estimated to 0.9 $\pm 0.1(P=0.05)$, while the square regression coefficient $\left(R^{2}\right)$ after the linear regression was found to be 0.99 (Table 1). These are good results because amplification efficiencies generally do not exceed 0.9 (17) due to factors affecting the amplification rate. Examples of standard curves for L. monocytogenes are shown in Figure 1 and amplification curves in Figure 2. The parallel behavior of the standard curves indicates similar efficiencies of $23 \mathrm{~S}$ and hlyA, and the calculations (Table 1) confirm this. A sensitive method to assess whether the two PCR products have identical efficiencies is to look at how $\Delta \mathrm{C}_{\mathrm{T}}$ between the two PCR products varies with template dilution (14). The results from this validation are summarized in Table 2. The absolute value of the slope of log input DNA versus $\Delta \mathrm{C}_{\mathrm{T}}$ $<0.5$ demonstrated that the amplification efficiencies of target and reference were approximately equal in the chosen range. The relative sensitivity $K_{R S}$ was
$0.9 \pm 0.2(P=0.05)$ (see Equation 2 in Materials and Methods). Thus, the effect of $K_{R S}$ is marginal for our primers and probes.

The number of 23S rRNA operons relative to hlyA was calculated using Equation 1 (Materials and Methods). To gain reliable discrimination of differences in copy numbers between two samples, it is preferable to calculate a mean of replicate determinations of the same sample (18). Initial estimations of the relative gene copy number of the 23S rRNA in L. monocytogenes strain L028 were therefore done on six samples. Since the amount of DNA added was identical in all tubes, the estimated ratio between $23 \mathrm{~S}$ and $h l y A$ was expected to be 6 , as indicated in an early study of the strain L028 (19), and confirmed by the complete sequencing of the $L$. monocytogenes EGD-e genome (20). The EGD-e strain used in our study is exactly the same as the genome sequenced strain and was received during the process of the genome sequencing. A comparative analysis of five different strains gave an estimate between 0.9 and 1.6 rRNA operons per hlyA gene copy (Table 2), reflecting $\Delta \mathrm{C}_{\mathrm{T}}$ values of approximately zero, instead of the expected $\Delta \mathrm{C}_{\mathrm{T}} \approx$ 2.8 (adjusted for the calculated amplification efficiency). The estimate using SYBR Green was a $\Delta C_{T} \approx-1$ for the EGD-e strain. There is probably a higher uncertainty SYBR Green than for the probe systems. This is because SYBR Green detects all that are amplified and because SYBR Green affects the amplification efficiency in a sequence-specific manner (21).

\section{Potential Effect of Point Mutations}

Potentially, the discrepancies could be correlated to mismatches in the primer or probe binding regions $(13,22)$ in the genomes. Therefore, we sequenced parts of both the 23S rRNA and hlyA genes in all strains used. These analyses showed no mutations in the primers and probes target sequences (data not shown). In addition, the sequencing of the complete EGD-e genome

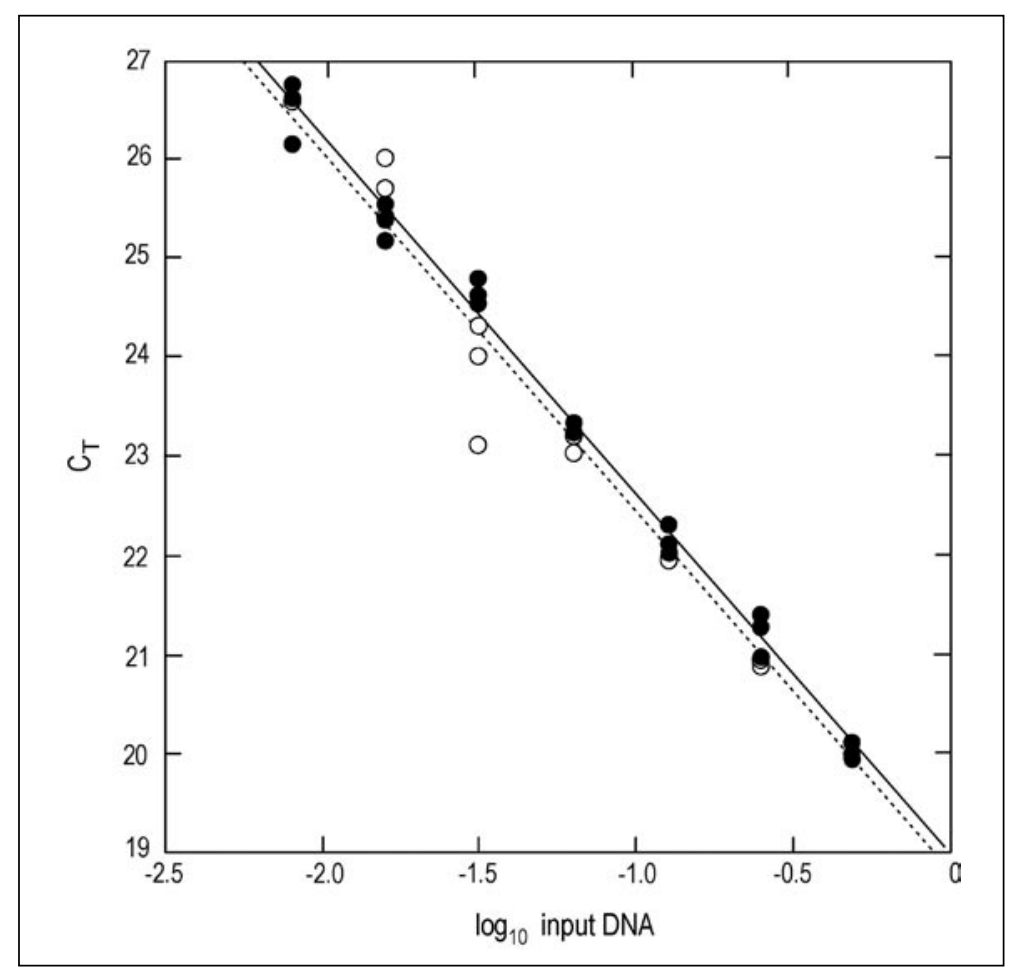

Figure 1. The detailed standard curves after amplification of the 23S rRNA gene ( 0 , dotted line) and the $h l y A$ gene $(\bullet$, continous line) for Listeria monocytogenes DSMZ $\mathbf{2 0 6 0 0}^{\mathrm{T}}$ (type strain). Cycle threshold $\left(\mathrm{C}_{\mathrm{T}}\right)$ values are plotted against log input DNA. The straight lines are calculated by linear regression, both demonstrating a slope of -3.6 and a square regression coefficient $\left(R^{2}\right)$ of 0.99 (Table 1$)$. 
Table 1. Analysis of the Quantitative Properties of 5'-Nuclease PCR Directed Toward the $h l y A$ and the 23S Genes in Listeria monocytogenes Strains

\begin{tabular}{|c|c|c|c|c|c|c|}
\hline \multirow[b]{2}{*}{ Strain } & \multicolumn{2}{|c|}{ Slope $^{a}$} & \multicolumn{2}{|c|}{ Efficiency $^{b}$} & \multicolumn{2}{|c|}{$R^{2 \mathrm{a}}$} \\
\hline & hlyA & $23 S$ & hlyA & $23 S$ & hlyA & $23 S$ \\
\hline DSMZ 20600' & -3.58 & -3.58 & 0.90 & 0.90 & 0.997 & 0.989 \\
\hline 2419 & -3.58 & -3.61 & 0.90 & 0.89 & 0.995 & 0.975 \\
\hline 3138 & -3.64 & -3.76 & 0.88 & 0.84 & 1.000 & 0.991 \\
\hline L028 & -3.74 & -4.11 & 0.85 & 0.75 & 0.998 & 0.999 \\
\hline EGD-e & -3.72 & -3.74 & 0.86 & 0.85 & 0.999 & 0.987 \\
\hline \multicolumn{7}{|c|}{$\begin{array}{l}\text { aStandard curves were estimated by drawing } x y \text { plots in Microsoft }{ }^{\circledR} \text { Exce } l^{\circledR} \text { with the log input amount } \\
\text { as the } x \text { value and cycle threshold }\left(C_{T}\right) \text { as the } y \text { value. The slopes and square regression coefficients } \\
\left(R^{2}\right) \text { were calculated using linear regression. } \\
\text { bThe efficiency was calculated according to Klein et al. (13), using the equation for efficiency: } \\
E=10^{(-1 / \text { slope })}-1 \text {. }\end{array}$} \\
\hline
\end{tabular}

revealed no mutations in the fragment chosen in the six rRNA operons (20). To investigate the possible causes for the miscalculations by the comparative gene quantification, we therefore took a closer look at the PCR process itself.

\section{Theoretical Evaluation of the Amplification Efficiency in the First PCR Cycles}

In PCR, there is a multiplicity of types of replicated molecules: native DNA, long products, and short products. In Figure 3, the discrete natures of the final products become evident. Whereas initial extension of the primers on native DNA results in products with definite $5^{\prime}$

ends but indefinite $3^{\prime}$ ends (long products), their extension on a long product results in a DNA strand that has both ends defined (short product). These single-stranded molecules may be thought of as those present in the middle of each cycle, immediately after the denaturation step. These can be defined as type 1 , type 2 , and type 3 , respectively (23).

It is the number of the type 3 fragments that increases exponentially during subsequent cycles. The number of type 2 fragments increase in a linear fashion, while the number of type 1 fragments is constant (Figure 3; Table 3). Together, the three types of fragments display geometrical amplification and fulfill the equation $2^{\mathrm{n}}$. The question is if all

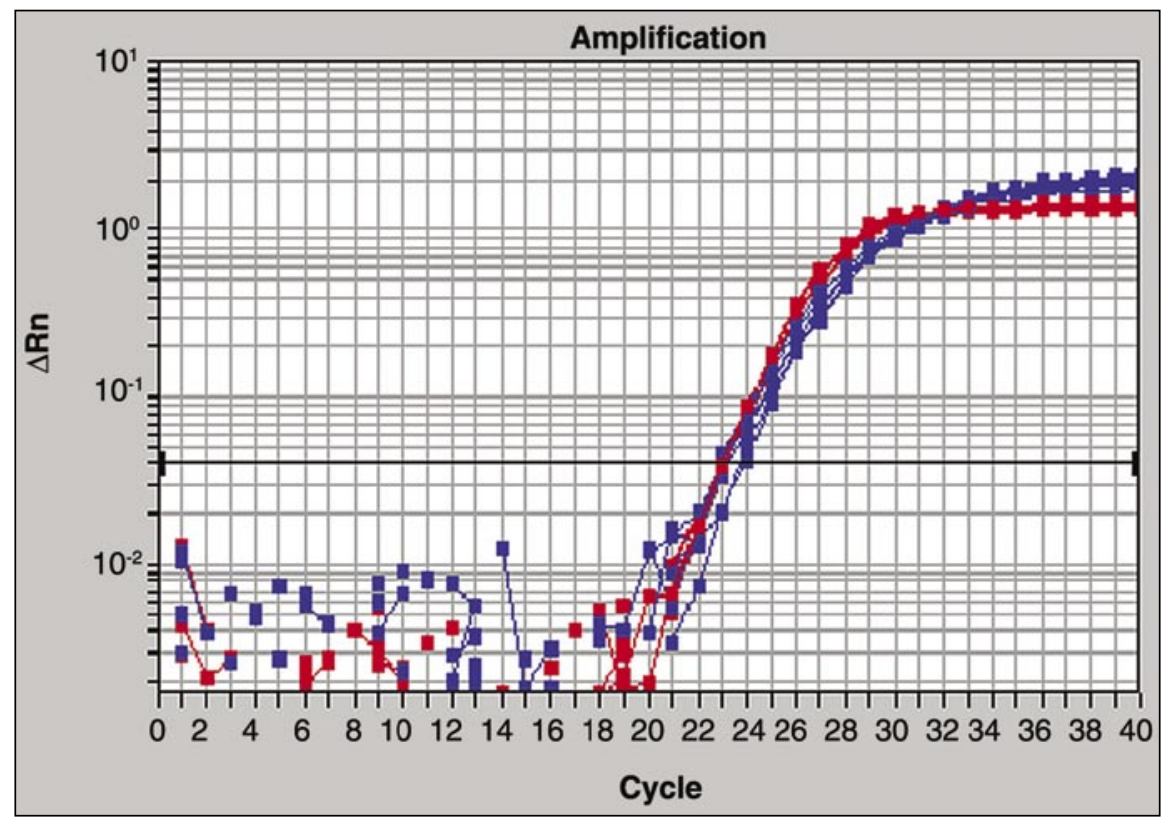

Figure 2. Amplification curves for the 23S rRNA gene (blue) and the hlyA gene (red). Amplification curves for three independent amplifications for both targets for the same DNA is shown. The DNA used is from the strain EGD-e. three types of molecules have the same probability of replicating. Chelly et al. (24) found that the average amplification efficiency was inversely related to fragment length. One can imagine several reasons for the three types of molecules to behave in separate manners (e.g., appearance of secondary structures). If the influences from secondary structures on amplification efficiencies vary in the type 1 and type 2 molecules in a target template versus a reference template, this could influence the analysis. Even if both type 3 fragments are amplified with identical average efficiency, as indicated in our validation experiments, it is not until the fifth cycle that the type 3 fragments start to dominate the outcome of PCR $(50 \%$ in cycle 4) (Figure 3; Table 3 ). This means that a lower amplification rate in the first cycles, due to less efficient amplification of the type 1 and type 2 fragments, will underreport the initial amount of targets.

The impact on the PCR efficiency by sequences upstream and downstream of the primer and probe binding sites have not been documented (25). Therefore, we used the DNA mfold server (16) to analyze the theoretical secondary structures and GC content of the three different types of templates, using $60^{\circ} \mathrm{C}$ as the folding temperature. The PCR fragments (type 3) adding 400-500 surrounding bases were chosen as type 1 molecules. The $23 \mathrm{~S}$ rDNA secondary structure created by mfold was almost 5.5 times as stable energetically $(\Delta \mathrm{G}=$ -8.2) as the corresponding hlyA rDNA secondary structure $(\Delta \mathrm{G}=-1.5)$.

Another reason for lower amplification efficiencies in the first cycles could be less efficient denaturation of the type 1 and type 2 fragments (26), since the efficiency is influenced by the melting temperature $\left(\mathrm{T}_{\mathrm{m}}\right)$ of the fragment. The chosen type 1 template had a $\mathrm{T}_{\mathrm{m}}$ of $70^{\circ} \mathrm{C}$ for $23 \mathrm{~S}$, while hlyA had a $\mathrm{T}_{\mathrm{m}}$ of $62.4^{\circ} \mathrm{C}$. Denaturation efficiencies could also be directly affected by the sequences outside the fragments defined by the primers. While $100 \mathrm{bp}$ upstream of the forward primer and the reverse primer in $23 \mathrm{~S}$ contained $58 \%$ and $53 \% \mathrm{GC}$, respectively, the corresponding GC contents were $42 \%$ and $31 \%$ in hlyA. Variations in the denaturation efficiency of the type 1 and type 2 fragments of $23 \mathrm{~S}$ and $h l y A$ could theoretically take place. 
Table 2. Comparative Quantification Data Including Validation

\begin{tabular}{|c|c|c|c|}
\hline Strain & $\begin{array}{c}\Delta \mathrm{C}_{\mathrm{T}^{\mathrm{a}}} \\
(\overline{\mathrm{X}} \pm \mathrm{SD})\end{array}$ & $\begin{array}{l}\text { Validation } \\
\text { (slope) }^{\mathrm{b}}\end{array}$ & $\begin{array}{l}\text { Relative 23S rDNA Operon } \\
\text { (copy number) }^{c}\end{array}$ \\
\hline DSMZ $20600^{\top}$ & $0.2 \pm 0.1$ & 0.005 & $1.1-1.2$ \\
\hline 2419 & $0.5 \pm 0.2$ & 0.027 & $1.2-1.6$ \\
\hline 3138 & $0.5 \pm 0.2$ & 0.117 & $1.2-1.6$ \\
\hline L028 & $-0.1 \pm 0.1$ & -0.074 & $0.9-1.0$ \\
\hline EGD-e & $0.2 \pm 0.2$ & -0.033 & $1.0-1.3$ \\
\hline \multicolumn{4}{|c|}{$\begin{array}{l}{ }^{a} \Delta C_{T} \text { was calculated by the subtraction of the average } h l y A \text { cycle threshold }\left(C_{T}\right) \text { value from the } \\
\text { average } 23 S C_{T} \text { value. The standard deviation of the difference is calculated from the stan- } \\
\text { dard deviations of the } 23 S \text { and } h l y A C_{T} \text { values. } \bar{x} \text {, mean. } \\
\text { bThe validation experiments were done by drawing xy plots in Microsoft Excel with the log } \\
\text { input amount as the } x \text { value and } \Delta C_{T} \text { as the } y \text { value. The slopes were calculated using linear } \\
\text { regression. } \\
\text { cThe range given for the relative DNA copy number was determined by using Equation } 1 \\
\text { (Materials and Methods). }\end{array}$} \\
\hline
\end{tabular}

\section{Evaluation of the Effect of Type 1 and Type 2 Fragments by Restriction Enzyme Digestion}

The rationale for digestion with restriction enzymes prior to amplification is the alteration of type 1 and 2 fragments. It is, of course, impossible to have a restriction enzyme that cuts exactly in the flanking regions of the primers. We used $A l u \mathrm{I}$ in our evaluations. This enzyme cuts $270 \mathrm{bp}$ upstream and 340 bp downstream of the hlyA PCR product (strain LO28), and 155 bp upstream and $40 \mathrm{bp}$ downstream of the 23S rRNA gene PCR product (strain ATCC 19115). All the strains described in Table 1 were analyzed. There was a clear decrease

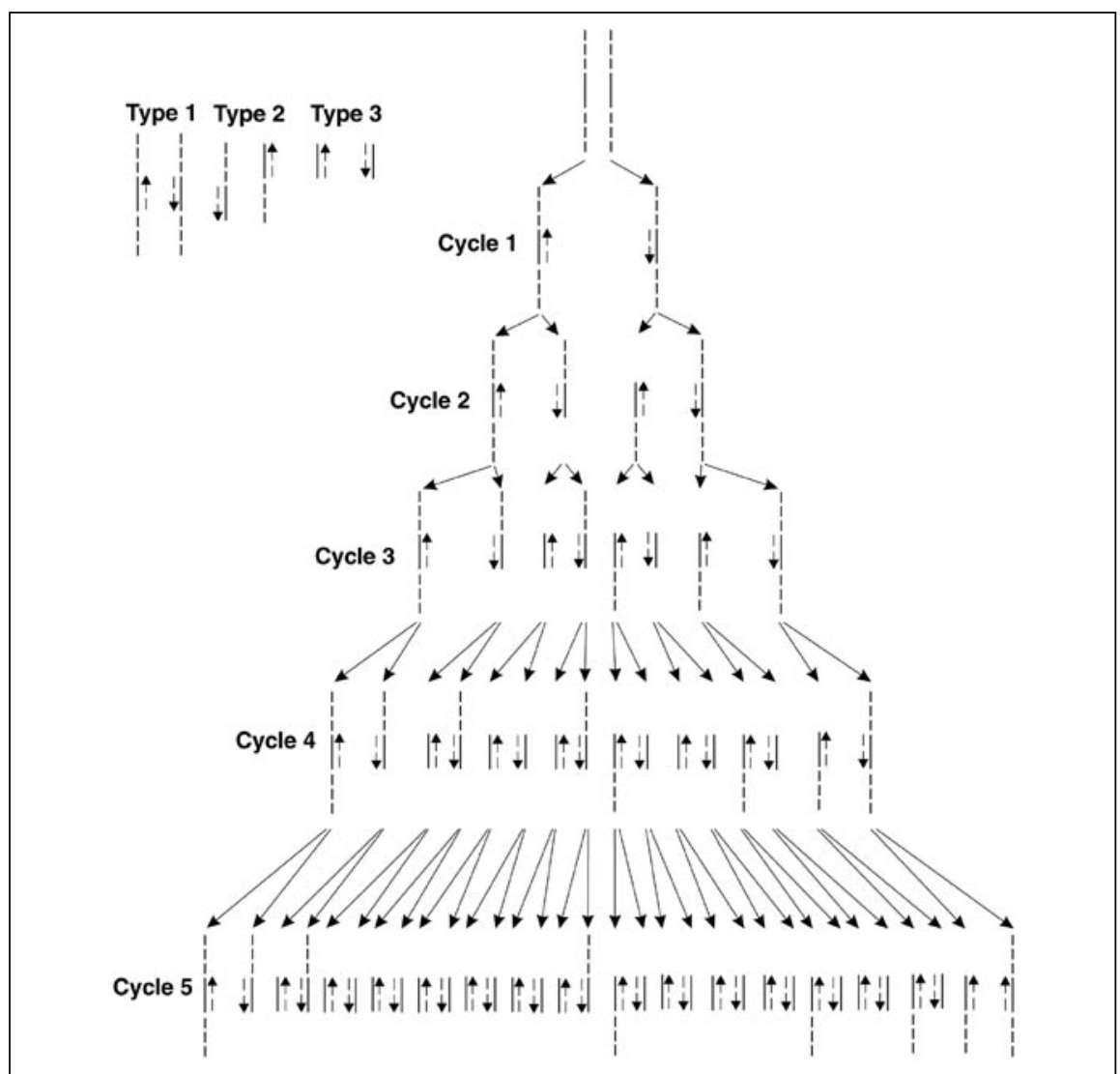

Figure 3. The first five cycles of PCR are visualized with the three different types of fragments, native DNA (type 1), long or intermediate products (type 2), and short products (type 3 ). The relative amounts of the three fragments are shown in Table 3. 
Table 3. Geometric Amplification and the Relative Amount of the Three Different Fragments Constituting the Six First Cycles in PCR

\begin{tabular}{|ccccc|}
\hline $\begin{array}{c}\text { Cycle } \\
\text { (No.) }\end{array}$ & $\begin{array}{c}\text { Geometric Amplification } \\
\mathbf{( 2}^{\mathbf{n}} \text { ) }\end{array}$ & $\begin{array}{c}\text { Type 1 } \\
\text { (native DNA) }\end{array}$ & $\begin{array}{c}\text { Type 2 } \\
\text { (long products) }\end{array}$ & $\begin{array}{c}\text { Type 3 } \\
\text { (short products) }\end{array}$ \\
\hline 1 & 2 & 2 & 0 & 0 \\
2 & 4 & 2 & 2 & 0 \\
3 & 8 & 2 & 4 & 2 \\
4 & 16 & 2 & 6 & 8 \\
5 & 32 & 2 & 8 & 22 \\
6 & 64 & 2 & 10 & 52 \\
\hline
\end{tabular}

(average $\Delta \mathrm{C}_{\mathrm{T}}=0.55 ; P=0.001$ ) for $h l y A$, with the largest difference for $L$. monocytogenes DSMZ $20600\left(\Delta \mathrm{C}_{\mathrm{T}}=\right.$ $1.5 ; P<0.0005)$. There was an effect for the $23 \mathrm{~S}$ rRNA gene, but it was not significant at the $5 \%$ level.

The effect of type 1 and 2 products for the 23S rRNA gene PCR product was evaluated further by cutting with all 10 possible pairwise combinations of the restriction enzymes $A l u \mathrm{I}, M s p \mathrm{I}, R s a \mathrm{I}$, and MseI for the DSMZ 20600 strain. The largest differences were obtained for $A l u \mathrm{I}$ alone $\left(\Delta \mathrm{C}_{\mathrm{T}}=0.8 ; P=0.001\right)$ and combinations of $A l u \mathrm{I}$ with $M s p \mathrm{I}$ and $M s e \mathrm{I}\left(\Delta \mathrm{C}_{\mathrm{T}}\right.$ $=0.29 ; P=0.001)$. The effect for the AluI and $R s a \mathrm{I}$ combination was lower and not significant. Interestingly, $R s a \mathrm{I}$ has a cutting site closer to the 23S PCR product, altering the upstream type 1 and 2 products compared to the AluI cutting. All other restriction enzymes cut outside $A l u \mathrm{I}$ on both sides of the PCR product. There were no detectable differences in the $\mathrm{C}_{\mathrm{T}}$ between the cut and uncut DNA for these enzyme combinations.

\section{DISCUSSION}

\section{Potential Probe Effects}

One possible explanation for the error in copy number determinations could be differences in the total signal intensities for the two target/probe systems. Another possibility could be that the probe cleavage was more efficient for the hlyA target than for 23S rRNA.

The relative sensitivity factor $K_{R S}$ is used to account for sensitivity differences between the target and the references. The calculation of $K_{R S}$ is, however, crucial. The $\mathrm{K}_{\mathrm{RS}}$ should be defined without assuming equal amplification efficiency from the first cycles until a signal can be detected (15) because it would not be possible to distinguish effects due to lower amplification efficiencies during the first cycles from the effects due to probe fluorescence and binding efficiencies. We based our $\mathrm{K}_{\mathrm{RS}}$ on the maximum difference in signals (before and after amplification) for the target and reference (Equation 2) to avoid this problem. This approach both takes into account the differences in probe binding and differences in fluorescence intensities for cleaved and uncleaved probes. Only a fraction of the probes will be cleaved during amplification for probes with low binding efficiencies, and the effect would be the same as for probes with low fluorescence efficiencies. Thus, the difference in signal before and after amplification would approximate the fluorescence and binding efficiencies.

We determined a $\mathrm{K}_{\mathrm{RS}}$ of approximately 0.9 for our target and reference system. Thus, the differences in relative sensitivity clearly cannot explain the error in copy number determinations. The difference should be very large (more than 5-fold) to explain the observed results.

\section{Effect of Type 1 and 2 Fragments}

A concern in standard design is that potential secondary structures of target and reference would induce different strand-separation, primer-annealing, and primer-extension kinetics during the first cycles (27). It should not be difficult to imagine that two different templates with different sets of primers and probes would experience different amplification efficiencies in the first cycles of PCR. We have done some theoretical calculations on this subject using the more detailed formula for geometrical amplification: $\mathrm{Nn}=\mathrm{N} 0(1+\mathrm{E}) \mathrm{n}$, where
E represents the mean efficiency of the amplification (value between 0 and 1). If the most efficient target is amplified at a mean efficiency of 0.9 , and the second target is amplified with a mean efficiency of 0.5 in the first three cycles, after the third cycle, even with six times the amount of target of the other, one is down to a 3-fold reduction in the amount of the two targets. If the situation is even worse, 0.9 and 0.3 in mean amplification efficiency, respectively, the difference in amount between the two targets is only twice when approaching the fourth cycle. Since the type 1 and 2 fragments still constitute $50 \%$ of the templates in cycle 4, one can expect the disproportion between the amplification efficiencies to further influence the yield of the two PCRs. Such effects in the first cycles would have serious implications on comparative gene quantification. If the differences between samples are small, there is a risk of an almost complete masking of the difference. In addition, the first few cycles of PCR constitute a screening phase, where each primer acts independently as a probe. Optimal screening or amplification requires different and sometimes antagonistic conditions (28).

What we have shown is that the $\mathrm{C}_{\mathrm{T}}$ values for the same amount of target DNA is affected by whether or not the DNA is cut. It is likely that the effect is due to the alteration of the type 1 and 2 PCR fragments, increasing the amplification efficiencies for these fragments. It is possible that the differences in amplification efficiencies for type 1,2, and type 3 fragments could contribute to incorrect gene copy number determinations using the comparative gene quantification method. Obtaining accurate proofs of the hypothesis, however, is very difficult. We are unable to determine the amplification efficiencies for the original type 1 and 2 fragments. Technical challenges are probably the reason why the question about the first PCR cycles has not promoted much attention in the literature using real-time PCR.

\section{Future Implications}

The general relevance of our observations has yet to be determined. However, if it is correct that the flank- 
ing regions are important for the quantitative results obtained, then this also has to be considered in fields other than comparative gene quantifications. For instance, in quantitative diagnostics, then slightly fragmented DNA would lead to higher determined amounts of a given target than intact DNA. It is clear that more research has to be focused on what is actually detected and quantified using real-time PCR.

\section{ACKNOWLEDGMENTS}

P. Glaser, representing the Listeria consortium, Insitute Pasteur, Paris, is acknowledged for providing the EGD-e strain, together with information about the genome sequence itself. P. Cossart, Institute Pasteur, is acknowledged for providing the L028 strain. This work was financed by the Research Levy for certain agricultural products.

\section{COMPETING INTERESTS STATEMENT}

The authors declare that they have no competing interests.

\section{REFERENCES}

1.Raeymaekers, L. 1995. A commentary on the practical applications of competitive PCR. Genome Res. 5:91-94.

2.Raeymaekers, L. 1993. Quantitative PCR: theoretical considerations with practical implications. Anal. Biochem. 214:582-585.

3.Saiki, R.K., S. Scharf, F. Faloona, K.B. Mullis, G.T. Horn, H.A. Erlich, and N. Arnheim. 1985. Enzymatic amplification of $\beta$-globin genomic sequences and restriction site analysis for diagnosis of sickle cell anemia. Science 230:1350-1354.

4.Sardelli, A.D. 1993. Plateau effect-understanding PCR limitations. Amplifications 9:2-5.

5.Linz, U., U. Delling, and H. RübsamenWaigmann. 1990. Systematic studies on parameters influencing the performance of the polymerase chain reaction. J. Clin. Chem. Clin. Biochem. 28:5-13.

6.Higuchi, R., G. Dollinger, P.S. Walsh, and R. Griffith. 1992. Simultanous amplification and detection of specific DNA sequences. Biotechnology 10:413-417.

7.Förster, V.Th. 1948. Zwischenmolekulare Energivanderung und Fluoreszenz. Ann. Physics (Leipzig) 2:55-75.

8.Bièche, I., M. Olivi, M.-H. Champème, D. Vidaud, R. Lidereau, and M. Vidaud. 1998. Novel approach to quantitative polymerase chain reaction using real-time detection: application to the detection of gene amplification in breast cancer. Int. J. Cancer 78:661-666.

9.Nogva, H.K., A. Bergh, A. Holck, and K. Rudi. 2000. Application of the $5^{\prime}$-nuclease PCR assay in evaluation and development of methods for quantitative detection of Campylobacter jejuni. Appl. Environ. Microbiol. 66:4029-4036.

10.Nogva, H.K., K. Rudi, K. Naterstad, A. Holck, and D. Lillehaug. 2000. Application of 5'-nuclease PCR for quantitative detection of Listeria monocytogenes in pure cultures, water, skim milk, and unpasteurized milk. Appl. Environ. Microbiol. 66:4266-4271.

11.Livak, K.J., J. Marmaro, and S. Flood. 1995. Guidelines for designing TaqMan fluorescent probes for $5^{\prime}$ nuclease assays. In Research News. Perkin-Elmer, Applied Biosystems, Foster City, CA.

12.Pearson, W.R. and D.J. Lipman. 1988. Improved tools for biological sequence comparison. Proc. Natl. Acad. Sci. USA 85:24442448.

13.Klein, D., P. Janda, R. Steinborn, M. Müller, B. Salmons, and W.H. Günzburg. 1999. Proviral load determination of different feline immunodeficiency virus isolates using realtime polymerase chain reaction: influence of mismatches on quantification. Electrophoresis 20:291-299.

14.Applied Biosystems. 1997. ABI Prism 7700 sequence detection system. User Bulletin \#2. Applied Biosystems, Foster City, CA.

15.Ståhlberg, A., P. Åman, B. Ridell, and M. Kubista. 2003. Quantiative real-time PCR method for detection of $\kappa$ and $\lambda$ immunoglobin light chain expression. Clin. Chem. 49:5159 .

16.SantaLucia, J., Jr. 1998. A unified view of polymer, dumbbell, and oligonucleotide DNA nearest-neighbor thermodynamics. Proc. Natl. Acad. Sci. USA 95:1460-1465.

17.Mathieu-Daude, F., J. Welsh, T. Vogt, and M. McClelland. 1996. DNA rehybridization during PCR: the "Cot effect" and its consequences. Nucleic Acids Res. 24:2080-2086.

18.Zimmerman, K. and J.W. Mannhalter. 1996. Technical aspects of quantitative competitive PCR. BioTechniques 21:268-279.

19.Michel, E. and P. Cossart. 1992. Physical map of the Listeria monocytogenes chromosome. J. Bacteriol. 174:7098-7103.

20.Glaser, P., L. Frangeul, C. Buchrieser, C. Rusniok, A. Amend, F. Baquero, P. Berche, H. Bloecker, et al. 2001. Comparative genomics of Listeria species. Science 294:849-852.

21.Giglio, S., P.T. Monis, and C.P. Saint. 2003. Demonstration of preferential binding of SYBR Green I to specific DNA fragments in real-time multiplex PCR. Nucleic Acids Res. 31:e136.

22.Kwok, S. and J. Sninsky. 1998. Present and future detection formats for PCR, p. 19-30. In F. Ferré (Ed.), Gene Quantification. Birkhäuser Boston, Cambridge, MA.

23.Nedelman, J., P. Heagerty, and C. Lawrence. 1992. Quantitative PCR with internal controls. Comput. Appl. Biosci. 8:65-70.

24.Chelly, J., D. Montarras, C. Pinset, Y. Berwald-Netter, J.-C. Kaplan, and A. Kahn. 1990. Quantitative estimation of minor
mRNAs by cDNA-polymerase chain reaction. Application to dystrophin mRNA in cultured myogenic and brain cells. Eur. J. Biochem. 18:691-698.

25.Freeman, W.M., J.W. Stephen, and K.E. Vrana. 1999. Quantitative RT-PCR: pitfalls and potential. BioTechniques 26:112-125.

26.Walsh, P.S., H. Erlich, and R. Higuchi. 1992. Preferential PCR amplification of alleles: mechanisms and solutions. PCR Methods Appl. 1:241-250.

27.Bloch, W. 1991. A biochemical perspective of the polymerase chain reaction. Biochemistry 30:2735-2747.

28.Ruano, G., D.E. Brash, and K.K. Kidd. 1991. PCR: the first few cycles. Amplifications $7: 1-4$

Received 2 February 2004; accepted 26 March 2004.

Address correspondence to:

Knut Rudi

MATFORSK, Osloveien 1

$N-1430$ Ås, Norway

e-mail: knut.rudi@matforsk.no 